\title{
Democracy in Education between Reality and Aspirations: Palestine as a Model
}

\author{
Mohammad Awad Shuibat ${ }^{1}$ \\ ${ }^{1}$ Al-Quds University, College of Educational Sciences \\ Correspondence: Mohammad Awad Shuibat, College of Educational Sciences, Al-Quds University, East \\ Jerusalem, West Bank- Palestine, POBox 20002.
}

Received: August 26, 2020

Accepted: October 9, 2020

Online Published: October 14, 2020

doi:10.5539/mas.v14n11p1

URL: https://doi.org/10.5539/mas.v14n11p1

\begin{abstract}
The research aims to study "education democracy " in terms of democratic practices in the educational process, developing a spirit of criticism, plurality of opinions, tolerance towards the opinions of others, respecting the decision of the majority and taking responsibility for the decision. In addition to the relationship between democracy and education, the relationship between democracy and education as a practice, and clarifying the goals of education for democracy, and clarifying areas of democratic awareness, the implications of education for democracy and procedures for developing democratic practices in education and the detection of obstacles to democratic practices in the educational process, and that is in the context of an applied analytical and scientific study based on the researcher's visit to Palestinian educational institutions and his knowledge of their reality, through which the researcher seeks to present what is hoped from the "education democracy" and how should it be applied to reality and what goals should these institutions seek to achieve?
\end{abstract}

Keywords: democratic practices, educational institutions, reality, aspirations, Palestine

\section{Introduction}

The democratic approach has evolved over the ages and its many concepts have varied, so that at present it is touching the various aspects of life and their fields on the individual and collective levels. There is no doubt that this development is the outcome of the accumulation of human thought throughout the ages, so it is the right of societies to practice and apply this approach in proportion to their values, beliefs and cultural, scientific heritage (Al-Shibani, 1986; Al-Rashdan, 2004).

Education is an important tool for achieving democracy, and democracy is an important tool for the advancement of the educational reality in order to build a civil society. Therefore, the relationship between democracy and education is a reciprocal dialectical relationship so that each of them rises dependent on and influenced by the other, and just as democracy opens only in an educated society, Education, too, does not develop in a way that encompasses equal opportunities for education except in a democratic atmosphere. Therefore, the philosophy of educational democracy lies in the fact that democracy can only be achieved in the field of education in a democratic context (Jaenini, 2004).

For democracy to become an approach and a way of life, an effective radical change must be made in the planning and implementation strategies, starting from the development of the educational leadership that represents the planning aspect, and the educational staff that represents the executive side, to accommodate democratic concepts such as: "Freedom, justice, equality, tolerance, human rights and acceptance of others"; considering that it represents the only guarantee for instilling those values and principles in the souls of young people, and giving them values that contradict slavery, negation and unilateralism. Without the conviction of young people how the continuity of change can be applied to reach a democratic society that appears in educational institutions?, especially since the major social change in the system of values and prevailing behavior depends on the extent of the change in educational institutions; That is, a society cannot live in a real democracy unless its educational institutions produce real democrats (Al-Batran, 2006).

The participatory and positive democratic behavior is based on the climate of freedom, equality, fairness, acceptance of the other, and teamwork, which in turn is reflected in the mental health of the parts of the educational process and is an indication of them at the same time, because the purpose of providing a healthy 
educational atmosphere is to achieve the desired goals and build effective human relations lean on the interaction which based on respect, trust, a sense of security and reassurance to maximize democratic behavior in education, whereas the more the educational system is flexible, able to satisfy the needs of learners and has the ability to inculcate the concepts of democracy and freedom, the more the learner is thinker and critic (Walter, 2003,17).

Based on the above, it is noticed that the voices of thinkers and scholars working in the educational field are getting loud towards the revolution on the methods of education and reconsidering the educational curricula and the means that enable the school to perform its tasks perfectly, and with that, it is also noticed that everyone agrees on the importance of democracy as a basis for education and an important lever in the success of the educational because democracy is a necessity in all aspects of life, but in education it has a special importance, whereas it is not real learning if democracy is not practiced in class during the educational-learning process.

Al-Amairah \& Mukabalih (2010) defined democracy as: A human system and a life style with its principles, concepts, knowledge and values, through which it is expected that their hopes and aspirations will be achieved including equality, justice, freedom, equal opportunities, tolerance, acceptance of the other and participation in decision-making "(p. 90).

\section{Literature Review}

After the researcher reviewed several studies on the subject, it was found that the practice of democracy in the educational process in Palestine came within the contemporary understanding of it, but it was below the required level, since democracy does not mean merely allowing individuals to enroll in education, but also ensuring equal educational opportunities, i.e. ensuring opportunities for success in it as well; in addition to the democratic interaction with students by teachers, developing a spirit of criticism, pluralism of opinions, and tolerance towards the opinions of others, and striving for excellence, respecting the decision of the majority and taking responsibility for the decision; as continuing education is not an independent evidence of a democracy in education; education is undemocratic if there are restrictions on subjects and knowledge, or if the relationships between administration, teacher and students are undemocratic, which leads to unintentionally giving negative values to the learner. Hence the urgent need to liberate knowledge from any form of control in its bureaucratic and ideological perspectives. And these are some studies which discussed democracy in the educational process:

Elise \& Mathe (2016): Which indicated that the students 'concept of democracy is elections or voting, the results of this study also revealed that students' understanding of the democracy term and its application to the ground came with a low degree.

Sanli (2015): Which aimed to identify the importance of achieving a democratic education environment at the school in Antalya - Turkey, the results of the research revealed that students' understanding of democratic education cannot take place in an authoritarian manner, but rather the student should be placed in the democratic axis so that he is sensitive to his rights and personality. The study confirmed that democracy is more acceptable systems of governance and control in our modern world, and that is why democratic education and achieving a democratic atmosphere in schools is important for students, teachers and administrators.

Al-shurman (2015): Which aimed to develop an understanding of the term democratic administrative education and its importance. The results of the study indicated that there is a great lack in schools of the appropriate atmosphere for the democratic process and its integration with education, as it has shown that directors deal with the democratic process and its concepts as values that cannot be applied to the ground. The study recommended providing a suitable environment for democratic practices, such as accepting others, freedom of expression and opening appropriate communication channels.

Subba (2014): Whose results confirmed that schools in India from teacher perspective is a place that instills democratic ideas such as equality, freedom and individual Justice in students, therefore teachers are the unlimited tools for change.

Al-Zabon (2008): Whose results showed that the majority of democratic practices of faculty members at Jerash University were in a moderate degree. The study recommended strengthening the faculty members with special courses in education and democratic practice and holding training courses for faculty members in how to deal with modern teaching methods and including some curricula of democratic concepts, methods of practice and principles, and the establishment of many dialogue meetings between students and faculty members to enhance communication and activate democratic practices between them.

Harb (2007): The results of this study confirmed that the degree of An-Najah National University students perceptions about democratic practices among faculty members was moderate. In the light of the results of the study, the researcher suggested several recommendations, the most important of which are: holding periodic 
intellectual and cultural seminars at the level of faculty members and students, and with the participation of the two parties at the university to devote the democratic concepts, values and practices.

\section{Theoretical Framework}

The current study defines the axes of democratic practices in the educational process based on the following points: the relationship between democracy and education, the relationship between democracy and education as a practice, the goals of education for democracy, the concept of education democracy and its practices, fields, contents and procedures in the democratic educational process, and the obstacles to the practice of democracy in the educational process in general and in the Palestinian reality in particular.

The concept of democratic education derives from the general concept of democracy, (Al-Shatti, 2003) defines democratic education as "Giving every citizen his right of education whatever the restrictions related to sex, gender, money, creed or color, and other differences and other differences that are not the fault of the individual" (p.6).

Radwan (2017) also defines it as "providing equal educational opportunities for everyone, according to what their preparations and capabilities allow, regardless of their economic and social level" (p.3). In the sense that everyone can find educational opportunities which appropriate for his tendencies and trends and learn to the extent that his abilities and preparations allow him to educate, taking into account the different personal and social characteristics.

Arousi (2008) indicates that contemplation on the concept of democracy confirms the existence of a loophole related to the social and economic variables experienced by the student, because difficult conditions limit his ability to use a private or public means to reach the required goals, and students must have the appropriate conditions in order to make learning more convenient and to facilitate the understanding of education, which means that there is an urgent need to provide the appropriate societal and domestic atmosphere for a proper education democracy to take place.

As for democratic practices, it means that education must have an educational interaction system between the elements of the educational process through the coordination of relations between teachers and students, and between students and students, and between teachers and educational administration (Al-Rumaidy, 2005).

Abu Zaid (2012) mentioned that there are three main dimensions of the concept of democratic education, which are:

- Learning democracy: In the sense that the educational system is built and its inputs, processes and practices are regulated in a way that achieves equal opportunities for the learner. And leads to the development of his personality to the maximum qualification based on his capabilities, preparations and tendencies, without his social and economic status standing in front of enrollment in the educational system and the educational advancement.

- Democracy in education: Managing, organizing and structuring the educational system at the various administrative and organizational levels: school, supervisory, local and central in a democratic manner that guarantees institutional participation, interaction and cooperation with various groups related to the educational process inside and outside the educational system.

Teaching democracy: Providing the learner with concepts, information, skills, values and trends related to democracy, by knowing the legislations, institutions, structures, democratic practices and relevant global models, with the aim of obtaining an education that helps the student to practice a democratic life and contribute to building a democratic society in the future.

\subsection{The Relationship between Democracy and Education}

Harb (2007) indicates that one of the main tasks in basic education institutions is to work in the service of the societies in which they provide their services, for the activities of these institutions to express the desire of their societies and their intellectual tendencies, and the most notable manifestations of the democracy are the efficient work with society and giving space to everyone who can benefit from education.

We can confirm that comprehensive democratic education shows levels of educational development in the way of building future generations and their personality so that the child becomes a creative human being, his behaviors are filled with positive trends that depend on the most important values of human society, and flexible in a way that made him able to deal with the positives produced by global civilization and then use it for the benefit of his society. Democratic education providing the future generation with renewable skills which helps them to contribute effectively to global civilization after building self-power according to the scientific methodology, and this is not done unless educational institutions worked to instill democracy in them, while preserving the right of the individual to think and express within a recognized value system. It also has to take a 
practical side with the breadth of its concept to be included in all areas of life and this, in turn, contributes to creating conscious generations, and innovative and creative energies that pursue development and renewal (Al-Ziadat, 2008).

Through our review of the nature of the educational system and its relationship to democracy during the past decades, we conclude that there is a close relationship between education and the political system, to the extent that the relationship has become more necessary and imperative in the democratic system in its broad sense as a social system based on an ethical and participatory basis, therefore, the relationship between democracy and education is an issue rooted in the depths of educational philosophies and educational policies in all advanced systems, as it is a cultural and social issue in its essence, and a natural extension of the development of society (Assaf, 2018). The result is what we know today as the term "education democracy", which refers to recognizing the need for intellectual and scientific independence for man and seeking to discover facts, get rid of the traditional authority in educational systems, avoid discrimination, give opportunities for scientific research and study for all by various interactive means away from dictatorial indoctrination by imposing the fait accompli (Marri, 2005).

Walter (2003) believed that one of the favorable means to achieve the proper concept of democracy in education is developing flexible curricula that are able to keep pace with and satisfy students' needs and help the student to be critical and thinker who has the freedom to deal with knowledge and concepts.

As for the Palestinian reality, it has been linked to severe effects on education, whether in curricula or in the dealings of teachers, educational management methods and teaching methods. In this context, Harb (2007) confirms that Palestinian youth in particular suffer a lot due to many circumstances such as the presence of occupation, including its repression, prosecution, arrest, and societal and value sabotage, which has caused great damage to society and its structures in general and youth in particular.

The suffering of the youth was exacerbated, especially during the Al-Aqsa Intifada, where the Israeli occupation systematically destroyed the structures of Palestinian society, as a result of these policies, especially since the suffering of this economic, social and psychological aspects has become obvious, which has reflected confusion and anxiety of the future. This, of course, will cause confinement or withdrawal from public work, in addition to searching for other ways of salvation, such as migration, travel, and possibly deviation, which requires who are in charge at the official and civil levels to give more effort in designing policies that will reduce the current impacts as a beginning to develop remedies and medium and long-term plans the outcome of which is putting the youth in their correct societal context, as a major force for change and renewal, which the researcher believes is important to take into account when talking about anything related to democratic practices in Palestinian education regardless of the different elements of the educational process.

Finally, democracy comes by education and socialization, not through intellectual, societal and biological heritage, and the signs and manifestations of it are not coming through what is transmitted by generations, and therefore democratic concepts cannot spread to various aspects of society suddenly and spontaneously, but rather remain merely slogans are not useful if they are not accompanied by field and real work.

Therefore, we note that there is a lot of confusion about that issue, and a lot of distinctive phrases in formulation but they are narrow in their meaning and the methods of application. If we want to spread democratic ideals in the different categories of the society, this needs to bring up children on practical democratic practices in the educational process and its various types on the ground, which means establishing the values of democracy in society, and therefore all of this is in the service of the country and patriotism (Abu Zaid, 2012).

\subsection{The Relationship between Democracy and Education as a Practice}

The theory of modernity brought by Seymour Lipset (1959) indicates that building and sustaining democracy in any country is based on the amount of economic and social development, as industrial and technological progress and increased levels of education all contribute to the transition to democracy. As education develops ways of human thinking and helps people to understand the principles of tolerance and prevents them from following the approach of extremism and develops their ability to elect their representatives rationally, and thus the theory confirms that the continuing education helps in the progress of society and the practice of democracy in its various institutions beginning with education itself.

Dewey (1944), stated that the criterion of criticizing and the form of democratic social life inside and outside the school must be based on the extent to which members of the group share their concerns or interests, and the freedom of this group to interact with other groups. 
In other words, a society is undesirable if it establishes internally and externally the barriers to freedom of interaction and the transfer of experience, while a society that provides its members with an equal sharing of their experiences, and ensures readjustment flexibly to its institutions through the interaction of mutual forms of social life is a democratic society, and such a society it must have a pattern of education that makes for its members a personal interest in relationships and social control and thinking habits that ensure social changes without resorting to disturbances. We conclude from the above that democratic systems must invest in education, as high levels of educational methods and democratic practice increase the society's tendencies towards democracy in general, this is clearly reflected on the development (Glaeser \& La porta, 2004). Accordingly, educational democracy can be embodied through the equitable distribution of educational benefits among members of society, whereas democracy in education is practiced by providing equal opportunities, advantages and capabilities equally among individuals, in order to obtain equal educational formation among members of society.

This definition of the concept of democracy in education moves towards new dimensions, which extend beyond the boundaries of the school institution to the depth of social and educational life (Wattfa, 2000).

\subsection{The Goals of Education for Democracy}

A number of educators pointed out that education for democracy has multiple goals that it seeks to achieve, including what was mentioned in Jeidory (2004):

First: Providing a democratic atmosphere.

In which each member of the family of the educational institution must adhere to the prevailing community philosophy and trends. And the more democracy tools and methods are used to achieve scientific, administrative, social and other relationships and interactions with each other; the more we created a suitable atmosphere for democratic exercise with its values based on freedom, security, justice, cooperation, responsibility and so on.

Second: Awareness of Democracy and Democratic Guidance.

These two processes are carried out through a group of different communication channels within the school or society as a whole, in several ways, including: lectures, seminars, debates, articles and research, all of which seek to confirm democratic concepts and trends, and activate the teachers 'relationship with students in a democratic framework

Third: Recognition of others as equivalents and openness to them.

That is, recognition of the equality of everyone in the dignity and the pluralism which is acceptable to all people, because effective tolerance requires an effort to know others and understand their differences and respect that difference, and training students to deal with other ideas and give them sufficient freedom even if they do not adopt them or deal with them.

\section{Fields, Contents and Procedures}

\subsection{The Fields of Democratic Awareness in School Education}

Perhaps one of the most important fields of awareness and democratic guidance: (Jeidory, 2004)

First - The scientific field of democratic practice within the educational institutions, life in any educational institution revolves to a large extent around two axes: the teacher and the student, so the more teachers presented the scientific and educational efforts that are appropriate to the needs of their students who invested these efforts carefully and seriously; the more positive the contribution of the educational institution in building democracy, perhaps one of the examples of these efforts is that the educational institution provides its students with better opportunities to reach a proper scientific level, by directing them to what suits their tendencies and abilities of types of education and its specializations, and this requires a method of educational guidance that starts from the first stages and continues until the student chooses his academic major in the university. Likewise, the educational institution shall sponsor the outstanding students with scientific care that prepares them to become scientists in their future specializations.

In addition to that the educational and scientific process in the institution must be based on the participation of students in planning their goals, preparing their study programs, discussing their lessons and assessing their scientific progress, as well as their participation in making decisions related to their scientific and practical reality, with an emphasis on the need for professors to address the mental and social trends that are inconsistent with the democratic practice by discussion, dialogue and persuasion. 
Second - The social field of democratic practice within the educational institution, so that both the democratic framework and school social life are appropriate for the social and democratic growth of students, and this can be accomplished by many means, including student councils where the students practicing their social life under the guidance of the teacher. Also, the relationship which based on respect and appreciation between the student and the teacher is considered one of the most important democratic means that achieve the ideal social life in educational institutions.

In addition to the importance of training students to practice freedom within a framework of discipline, and to choose criteria that suit them and does not conflict with the values of society, to use them in evaluating their use of freedom, that is, the student assesses his behavior and freedom in the light of these criteria. Hence, it is the responsibility of our educational institutions to work towards achieving democratic growth for their students in the scientific and social fields in light of a democratic atmosphere. Whereas, if students are trained to improve the selection of their representatives and the choice of their decisions, and practice democratic life, as leaders sometimes and followers at other times, this will provide many opportunities to deepen the values of cooperation, respect the others, take responsibility, and other forms of democratic behavior that are necessary prelude to build a democratic society.

\subsection{Education for Democracy Contents}

A group of contents work together to build a robust and firm democracy that can be localized within society, by using it in education in a way that helps in achieving coherent democratic principles. the most notable of these contents are:

First: Human rights.

It is the responsibility of education for democracy to transmit basic knowledge about human rights and fundamental freedoms in the first place, because these rights have a civilized value whose importance is that urban countries work to establish, respect, protect, and guarantee them for its individuals who understand, appreciate, and respect human rights, and then defend them and work to protect them, as well as the need to deal with them as a civilized issue, and it is remarkable that since the Universal Declaration of Human Rights issued by United Nations General Assembly on the tenth of December 1948, the issue of human rights education is receiving great attention at the international level, where the declaration of the General Assembly issued on December 7, 1965 stated that young people should be taught the values of peace, justice, freedom and mutual respect between peoples. As stated in UNESCO recommendation in1974 that member states should take adequate steps to make the principles of the Universal Declaration of Human Rights and the International Convention on the Elimination of All Forms of Racial Discrimination effective when practicing the education process at all levels and forms (UNESCO, 1994, 3).

The researcher believes that it is the duty of decision-makers in Palestine, as its people are oppressed and suffering as a result of the occupation and its flagrant violations of human rights, to deepen students' understanding of the principles of human rights and their rights and duties towards themselves, their homeland and the peoples of the earth, and this requires the inclusion of these principles in the school curricula Educational.

Second: Human rights values and principles.

This item focuses on the contribution of education to cultural development, improving policies and educational materials, and preparing teachers to keep abreast of everything related to intercultural education through education, moral, cultural and human values, knowledge of other cultures and the understanding of the cultural heritage of humanity (UNESCO, 1993, 1-2).

\subsection{Procedures for Developing Democratic Practice in Education}

Abdul-Mahdi (2006) refers to a set of procedures that can be applied to practice democracy within the educational process in a progressive and improving manner, and these procedures include:

1. The comprehensive change in the academic subjects and the educational system, by providing freedom of education and modifying the curricula, concepts and educational programs, to make them focus on justice between social groups, abolishing class inequalities and creating a national feeling based on the nation and its interest in the first place in the hierarchy of interests.

2. Commitment to objectivity in the teaching of information, materials and concepts.

3. The comprehensive liberation of the educational process: This is done through a national project that carries within it the foundations of absolute belief in the human ability to create and originate, and the ability of society to rely on itself in the work to progress and develop to spread democracy. 


\subsection{The Obstacles to Practicing Democracy in the Educational Process}

(Bougherra, 2008) indicates that there are a set of obstacles that obstruct the practice of democracy in the educational process, the most important of which are:

First: Institutional obstacles.

Among the most important obstacles that stem from the prevailing culture in the institution, especially in its management, which reflects itself, and implicitly, on the general condition of the teacher. If these values make workers just executors of orders, this will lead to frustration of the democratic style which based on thinking and criticism.

The researcher noted, through working in the teaching field and dealing with a wide range of departments and teachers, that there is an ongoing complaint from teachers regarding dealing with this dictatorial pattern so that democracy is just a superficial concept not a cultural and intellectual legacy to be used and applied.

Second: Obstacles arising from the managers themselves.

These obstacles stem from the natural tendency of the managers to retain the authority and responsibility of the school and in many cases the managers feel fear and suspicion towards the call to delegate powers and responsibilities to the workers. All of these matters undoubtedly reflect negatively on the effectiveness of the teachers and their participation in managing the various aspects of the school.

In this regard, the researcher indicates that managers sometimes tend to convert the institution into the one man show pattern, which is the old prevailing pattern in global management that leads, over time, to the teacher's feeling that it is only a machine that works to achieve the interests of the manager only.

Third: Obstacles related to the employees.

We often encounter teachers who see that their role in school is merely to teach the courses they are assigned to teach only, and that just giving them new responsibilities even if with some powers they consider it an additional burden placed on them, and this matter certainly stands in the way of activating the democratic style in managing their schools.

The researcher indicates that this may be related to the obstacles mentioned in the previous two axes, as what the teacher faces from dictatorial administrative deal, feeling of absolute dependence, lack of appreciation and lack of achievement all lead to a tendency towards traditional teaching with the least possible effort to suit the minimum level of work.

We conclude from the above the necessity to agree with Abu Zayd (2012) on his findings that the real problem facing the reinforcement of democratic concepts in the educational institution is the bureaucratic pattern of educational management starting with the manager who is (the center) and ending with the rest of the individuals, in addition to the lack of efficiency and experience in managing the educational institution, and this is what prevents the democratic transformation in the educational institution. As for the teacher, he needs more elements of vision and performance in implementing the curriculum and achieving educational goals, due to the absence of the real institution in which the means of preparing him are available. He is not seeking to creativity and development within the educational institution and this is what makes the democratic practice in the educational institution ineffective and perfunctory.

Based on the above: The researcher believes that studying the reality of educational institutions is extremely important; due to the importance of practicing the principles of democracy as a behavior and life style for the advancement of the individual and society alike, because freedom of expression of opinion, non-discrimination, acceptance of the other, equality of opportunity, justice and equality among the most important pillars of democracy.

\section{References}

Abdul-Mahdi, Salah. (2006). Education democracy and its obstacles in Iraq. Al Furat Center for Development and Strategic Studies, The second article, Baghdad.

Abu Zaid, Zaid. (2012). The democratic foundations of education - education and democracy. Education and Culture Journal, article on April 23. Retrieved from http://al3loom.com/?m=201204

Al-Rashdan, Abdullah. (2004). Educational Sociology. Dar Al-Shorouq, Amman.

Al-Amairah, Mohammed, \& Mukabalih, Atef. (2010). Students' evaluation of the role of high school in providing them with the culture of democracy and their behavior in light of the democratic transformation of Jordanian society from their point of view. Al- Quds Open University Journal for Research and Studies, (21), 79-126.

Al-Batran, Ashraf. (2006). Education and democracy: an absent relationship. Ru'a Tarbawiyya Journal, (21), $129-127$ 
Al-Rumaidy, Khalid. (2005). Democratic educational practices in the Kuwaiti school (Views of a sample of fourth secondary students in Kuwait). Damascus University Journal, 26(4), 155-213.

Al-Shatti, Ismail, et al. (2003). Entrances to the transition to democracy in the Arab countries. Center for Arab Unity Studies, Beirut.

Al-Zabon, Saleem. (2008). Democratic practices of the faculty members at Jerash University from the viewpoint of their students. Journal of Educational Sciences, 38(2), 650-664.

Al-Ziadat, Maher. (2008). The effectiveness of a proposed educational program in acquiring the tenth grade students for democratic concepts in the subject of national and civic education in Jordan. Journal of the Islamic University, Series of Humanities, 16(2), 533-553.

Arousi, Suhail. (2008). Civil Society and the State: A study of the structure and significance of civil society and the state and its relationship to democracy. Dar Al-Fikr Publishing, Damascus.

Assaf, Mahmoud Abdel-Majid Rashid. (2018). The degree of response of the Palestinian school curricula in the basic stage to the features of democratic education from the teachers point of view. Journal of the College of Basic Education for Educational and Human Sciences, (39), 165-148.

Bougherra, Awatef. (2008). The degree to which high school principals apply the principles of democratic management from teachers point of view. Unpublished Master Thesis, University of Batna 1 - Hadj Lakhdar, Algeria.

Dewey, John. (1944). Democracy and education. The Free Press, New York.

Elise, N. M, Hesby. (2016). Students' Understanding of the Concept of Democracy and Implications for Teacher Education in Social Studies. Acta Didactica Norge, 10(2), 271-289. https://doi.org/10.5617/adno.2437

Glaeser, E., La Porta R., Florencio Lopez-de-Silanes, \& Andrei Shleifer. (2004). Do Institutions Cause Growth? Journal of Economic Growth, (9), 271-303. https://doi.org/10.1023/B:JOEG.0000038933.16398.ed

Harb, Rola. (2007). Perceptions of An-Najah University students of the democratic practices of faculty members. Unpublished Master Thesis, An-Najah University, Palestine.

Jaenini, Naeem. (2004). Philosophy and its educational applications. Dar Wael, Amman.

Jeidory, Saber. (2004). Education and democracy. Damascus University, Syria.

Lipset, S. M. (1959). Some Social Requisites of Democracy: Economic Development and Political Legitimacy. American Political Science Review, 53(1), 69-105. https://doi.org/10.2307/1951731

Marri, J. (2005). The case of Democratic schools. ASCD Journal, 11(2), 116-132.

Radwan, Hanan. (2017). Educational justice and its relationship to equal educational opportunities and education democracy. Unpublished PhD Thesis, Benha University, Egypt.

Sanli, O. (2015). The Significance of establishing Democratic education Environment at Schools. Journal of Educational and Instructional Studies in the World, 5(2), 256-310.

Subba, Dipty. (2014). Democratic Values and Democratic Approach in Teaching: A Perspective. American Journal of Educational Research, 2(12), 37-40.

UNESCO. (1993). Recommendations on education for international understanding, cooperation and peace, and education in the field of human rights and fundamental freedoms. The 27 th session, Paris.

UNESCO. (1994). Recommendations on education for international understanding, cooperation and peace, and education in the field of human rights and fundamental freedoms. Session, (18), Paris.

United Nations. (2003). Universal Declaration of Human Rights. United Nations site on management media affairs, available on the internet page on the following website on 12-25-2008. Retrieved from http://www.un.org/arabic/aboutun/humanr.html

Walter, Parker. (2003). Teaching Democracy. Teacher College, Columbia University, New York.

Wattfa, Ali. (2000). The structure of authority and the problem of educational authoritarianism in the Arab world. Center for Arab Unity Studies, Beirut.

\section{Copyrights}

Copyright for this article is retained by the author(s), with first publication rights granted to the journal.

This is an open-access article distributed under the terms and conditions of the Creative Commons Attribution license (http://creativecommons.org/licenses/by/4.0/). 